
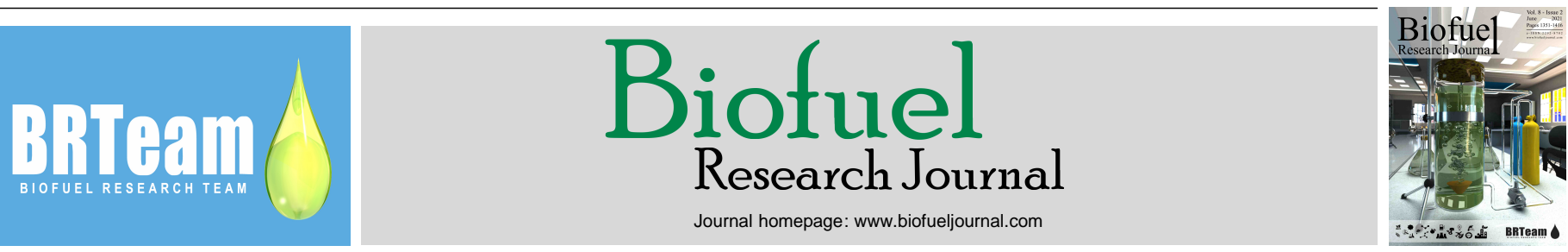

Original Research Paper

\title{
Effects of particle size of cerium oxide nanoparticles on the combustion behavior and exhaust emissions of a diesel engine powered by biodiesel/diesel blend
}

\author{
P. Dinesha ${ }^{1}$, Shiva Kumar ${ }^{1, *}$, Marc A. Rosen ${ }^{2}$ \\ ${ }^{I}$ Department of Mechanical and Manufacturing Engineering, Manipal Institute of Technology, Manipal Academy of Higher Education, Manipal-576104, India. \\ ${ }^{2}$ Faculty of Engineering and Applied Science, University of Ontario Institute of Technology, 2000 Simcoe Street North, Oshawa, Ontario, L1 G 0C5, Canada.
}

\section{HIGHLIGHTS}

$>$ Effects of different sizes of $\mathrm{CeO}_{2}$ nanoparticles on diesel engine combustion was studied. $>$ Biodiesel-diesel blend harboring $\mathrm{CeO}_{2}$ nanoparticles of different sizes, i.e., 10,30 , and 80 $\mathrm{nm}$ were compared.

$>$ Fuel consumption dropped by $2.5 \%$ for $30 \mathrm{~nm}$ nanoparticles-doped fuel blend vs. its additive-free counterpart.

$>$ Smoke opacity and NOx concentration decreased by $34.7 \%$ and $15.7 \%$ for fuel formulation harboring $30 \mathrm{~nm} \mathrm{CeO} 2$ nanoparticles.

\section{GRAPHICAL ABSTRACT}

$\mathrm{CeO}_{2}$ Nanoparticles

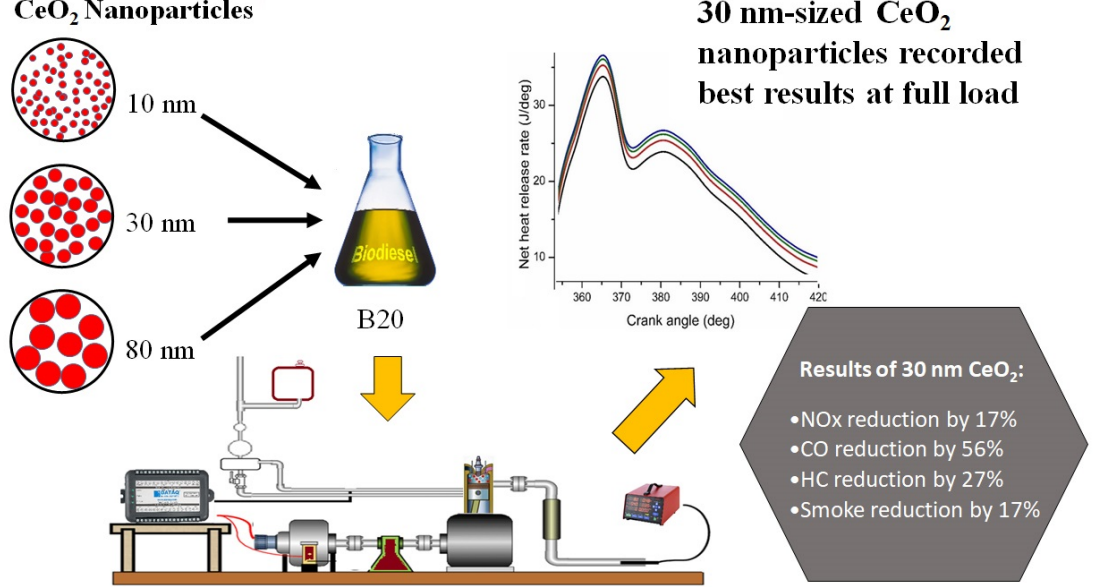

\section{ARTICLE INFO}

\section{Article history:}

Received 19 February 2021

Received in revised form 19 April 2021

Accepted 23 April 2021

Available online 1 June 2021

\section{Keywords:}

Diesel engine

Engine performance

Exhaust emissions

Fuel formulation

Nanoparticles

Nanoparticle size

\begin{abstract}
Meeting the emission norms specified by governing bodies is one of the major challenges faced by engine manufacturers, especially without sacrificing engine performance and fuel economy. Several methods and techniques are being used globally to reduce engine emissions. Even though emissions can be reduced, doing so usually entails a deterioration in performance. To address this problem, nanoadditives such as cerium oxide $\left(\mathrm{CeO}_{2}\right)$ nanoparticles are used to reduce engine emissions while improving engine performance. However, some aspects of the application of these nanoadditives are still unknown. In light of that, three sizes of $\mathrm{CeO}_{2}$ nanoparticles (i.e., 10, 30, and $80 \mathrm{~nm}$ ) and at a constant volume fraction of 80 ppm were added to a $20 \%$ blend of waste cooking oil biodiesel and diesel (B20). A single-cylinder diesel engine operating at a $1500 \mathrm{rpm}$ speed and 180 bar fuel injection pressure was used to compare the performance and emission characteristics of the investigated fuel formulations. The results showed that the addition of $\mathrm{CeO}_{2}$ nanoparticles led to performance improvements by reducing brake specific fuel consumption. Moreover, the catalytic action of $\mathrm{CeO}_{2}$ nanoparticles on the hydrocarbons helped achieve effective combustion and reduce the emission of carbon monoxide, unburnt hydrocarbon, oxides of nitrogen, and soot. Interestingly, the size of the nanoadditive played an instrumental role in the improvements achieved, and the use of $30 \mathrm{~nm}$-sized nanoparticles led to the most favorable performance and the lowest engine emissions. More specifically, the fuel formulation harboring $30 \mathrm{~nm}$ nanoceria reduced brake specific fuel consumption by $2.5 \%$, NOx emission by $15.7 \%$, and smoke opacity by $34.7 \%$, compared to the additive-free B20. These findings could shed light on the action mechanism of fuel nanoadditives and are expected to pave the way for future research to develop more promising fuel nanoadditives for commercial applications.
\end{abstract}

(c) 2021 BRTeam. All rights reserved.

* Corresponding author at: Tel.: +91 9449269099

E-mail address:

Please cite this article as: Dinesha P., Kumar S., Rosen M.A. Effects of particle size of cerium oxide nanoparticles on the combustion behavior and exhaust emissions of a diesel engine powered by biodiesel/diesel blend. Biofuel Research Journal 30 (2021) 1374-1383. DOI: 10.18331/BRJ2021.8.2.3 


\section{Contents}

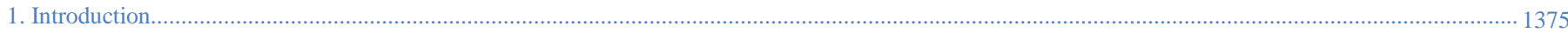

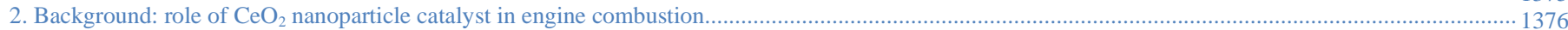

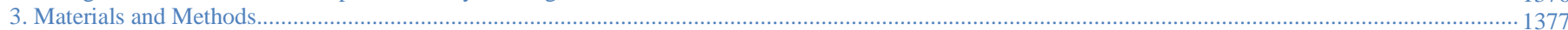

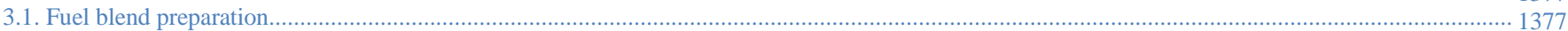

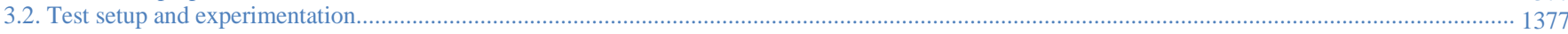

3.3. Heat release rate

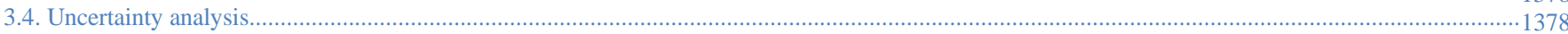

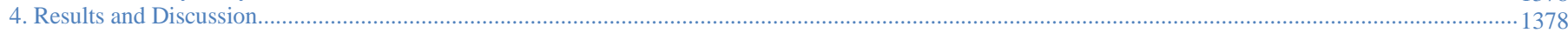

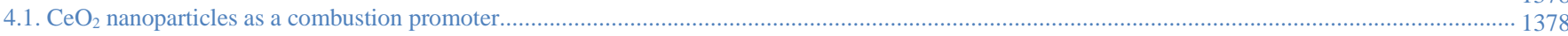

4.1.1. Cylinder peak pressure and heat release rate

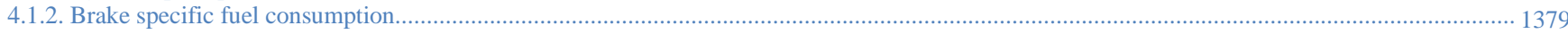

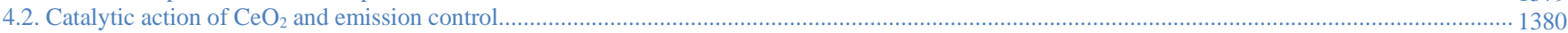

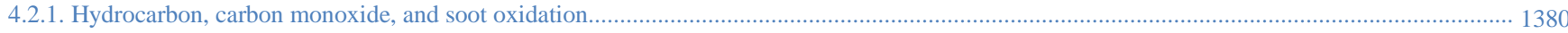

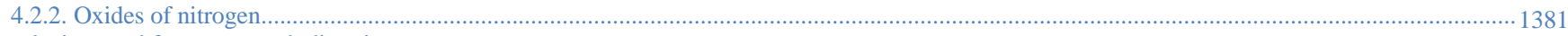

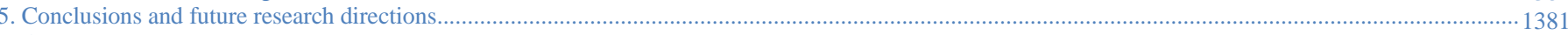

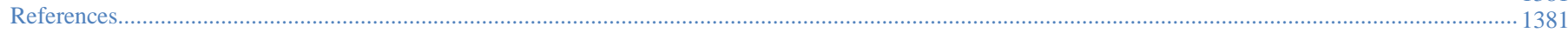

\begin{tabular}{|ll|}
\hline Abbreviations & \\
$\mathrm{B} 20$ & $20 \%$ WCO biodiesel and $80 \%$ mineral diesel \\
$\mathrm{B} 20+10 \mathrm{~nm}$ & $\mathrm{~B} 20+10 \mathrm{~nm} \mathrm{CeO}_{2}$ \\
$\mathrm{~B} 20+30 \mathrm{~nm}$ & $\mathrm{~B} 20+30 \mathrm{~nm} \mathrm{CeO}_{2}$ \\
$\mathrm{~B} 20+80 \mathrm{~nm}$ & $\mathrm{~B} 20+80 \mathrm{~nm} \mathrm{CeO}_{2}$ \\
$\mathrm{BSEC}$ & Brake specific energy consumption $(\mathrm{MJ} / \mathrm{kWh})$ \\
$\mathrm{BTE}$ & Brake thermal efficiency $(\%)$ \\
$\mathrm{CeO}_{2}$ & Cerium oxide \\
$\mathrm{Ce}_{2} \mathrm{O}_{3}$ & Cerous oxide \\
$\mathrm{D}_{\mathrm{p}}$ & Nanoparticle diameter (nm) \\
$\mathrm{dQ} \mathrm{N} / \mathrm{d} \theta$ & Instantaneous heat release rate (J/deg. CA) \\
$\mathrm{HSU}$ & Hartridge smoke unit \\
$\mathrm{K}_{\mathrm{f}}$ & Base fluid thermal conductivity (W/mK) \\
$\mathrm{K}_{\mathrm{n}}$ & Nanofluid thermal conductivity (W/mK) \\
$\mathrm{K}_{\mathrm{p}}$ & Nanoparticle thermal conductivity (W/mK) \\
$\mathrm{p}$ & Pressure (bar) \\
$\mathrm{X}_{\mathrm{CO}}$ & Carbon monoxide concentration (\%vol) \\
$\mathrm{X}_{\mathrm{CO} 2}$ & Carbon dioxide concentration $(\% \mathrm{vol})$ \\
$\mathrm{X}_{\mathrm{HC}}$ & Hydrocarbons concentration (ppm) \\
$\mathrm{X}_{\mathrm{NOx}}$ & Oxides of nitrogen concentration (ppm) \\
$\mathrm{WCO}$ & Waste cooking oil \\
$\mathrm{T}$ & Temperature $\left({ }^{\circ} \mathrm{C}\right)$ \\
$\mathrm{V}$ & Volume (m $\left.{ }^{3}\right)$ \\
$\gamma$ & Ratio of specific heats \\
$\varepsilon$ & Volume fraction of nanoparticles (\%) \\
\hline & \\
\hline
\end{tabular}

\section{Introduction}

Diesel fueled engines are commonly used prime movers in the transport and industrial sectors, partly because they have high thermal efficiencies and good reliability. Dependence on diesel engines has increased, leading to elevated fossil fuel consumption. On the other hand, the largest sources of greenhouse gas emissions are prime movers that use conventional fuels such as diesel (Agarwal, 2007). Substituting fossil fuels with renewable options such as biofuels can help reduce carbon emissions (Kumar and Dinesha, 2019).

Vegetable oil and animal fat serve as raw materials for the manufacturing of biodiesel. Transesterification redefines the molecular structure of the materials involved in producing biodiesel, rendering it suitable as an alternative for diesel engines (Rakopoulos et al., 2006; Sureshkumar et al., 2008; Muralidharan et al., 2011). Neat biodiesel suffers certain shortcomings like increased NOx, low energy output, and high specific fuel consumption (An et al., 2013). The usage of additives has been shown to be able to overcome these limitations by meeting specific fuel requirements (Agarwal et al., 2008; Alptekin, 2017; Dinesha et al., 2019). Marginal reductions in emissions are observed when using microscale sized additives, but studies indicate that the usage of large additive particles could adversely affect combustion performance, leading to increases in emissions and decreases in efficiency (Bertola et al., 2003; Qi et al., 2009; Izquierdo et al., 2012). This phenomenon could be explained by the higher density of the additive-containing droplets, making it difficult to have a uniform mixture of fuel and additives. This could also result in the settling of the additive-containing droplets, leading to sedimentation. Another disadvantage is that when larger particles are injected along with the base fuel, they take more time to complete physical and chemical processes, resulting in higher ignition delay. A higher delay period leads to incomplete combustion and increased exhaust emissions. Hence, these factors limit the use of large-sized additives in biodiesel blends.

Nevertheless, these limitations can be overcome by applying nano-sized metal or metal oxide particles $(<100 \mathrm{~nm})$ in biodiesel blends. They have specific advantages such as higher surface to volume ratio, higher thermal conductivity, and better lubricating properties than micro-sized additives (Kumar et al., 2018; Kumar et al., 2019a). When nanoparticles are mixed with a base fluid such as water, diesel, biodiesel, etc., the resulting mixture is known as a nanofluid. Compared to the base fluid, the nanofluid has distinct advantages like higher thermal conductivity and improved lubricity. These properties help with the efficient transfer of heat, which is essential during engine combustion. Furthermore, relatively smal diameters of nanoparticles reduce sedimentation by enhancing their dispersion and also increasing chaotic movements. When a nanofluid is injected through the fuel injector into the combustion chamber, an increase in heat exchange between biodiesel and air could be achieved due to the nanofluid's higher thermal conductivity mentioned earlier. This quickly prepares the air-fuel mixture to undergo spontaneous combustion compared to neat fuel combustion, reducing ignition delay. Hence, enhanced combustion and engine performance can be achieved with lower emissions.

Powering diesel engines with biodiesel formulations harboring nanoparticle additives have been investigated experimentally. Rao and Dash (2015) studied the role of particle size on the spreading stability of aluminum nanoparticles (13 $\mathrm{nm}$ and $28 \mathrm{~nm}$ in size) after their addition to Jatropha-based biodiesel. They reported that the $13 \mathrm{~nm}$ nanoparticles with a $0.1 \%$ volume fraction were stable for more than one year. Kumar et al. (2017) investigated the influence of ferric nanoparticles on the performance and emissions characteristics of a diesel engine powered by biodiesel. On adding $1 \%(\mathrm{v} / \mathrm{v})$ of ferrofluid nanoadditive to B20, the authors observed a higher brake thermal efficiency (BTE), lower fuel consumption, and lower concentrations of carbon monoxide $\left(\mathrm{X}_{\mathrm{CO}}\right)$ and hydrocarbon $\left(\mathrm{X}_{\mathrm{HC}}\right)$. Prabu (2018) experimentally studied the operational characteristics of a conventional diesel-fueled engine with alumina $\left(\mathrm{Al}_{2} \mathrm{O}_{3}\right)$ and ceria $\left(\mathrm{CeO}_{2}\right)$ nanoparticles. They reported that $\mathrm{Al}_{2} \mathrm{O}_{3}$ as a nanoadditive yielded a higher BTE than the nanoceria and that the presence of nanoparticles, in general, diminished the delay and accelerated early initiation of combustion.

Ramesh et al. (2018) investigated the effects of adding alumina-based nanoparticles into poultry litter-based biodiesel on the performance, emissions, and combustion behavior of a diesel engine. They reported that biodiesel with alumina nanoparticles exhibited a better BTE than neat biodiesel fuel. D'Silva et al. (2019) studied the effects of titanium dioxide nanoparticles (25, 50, and 75 ppm) inclusion in Pongamia biodiesel (B20) 
on diesel engine combustion. More efficient fuel combustion was noticed for the nanoparticle-blended fuels with considerably reduced emissions, except for nitrogen oxides $\left(\mathrm{NO}_{\mathrm{X}}\right)$. The authors highlighted that the fuel blend harboring $75 \mathrm{ppm}$ nanoparticles exhibited the most promising results. Kao et al. (2007) performed combustion experiments on a diesel engine using fuels containing an aqueous aluminum nanofluid. They observed an improvement in burning rate in the presence of the aqueous aluminum nanofluid. Similarly, Xin et al. (2013) argued that the addition of nanoceria as nanoadditive improved the combustion efficiency, likely due to the elevated pressure and extension in burning duration.

It has also been reported that nanoparticle-blended fuels were associated with shorter ignition delays vs. conventional diesel fuel and that the maximum achievable cylinder pressure of fuel blends with nanoparticles was more significant than that for neat conventional diesel (Kumar et al., 2019a). Kumar et al. (2019b) tested the combined impact of injection pressure (180, 210, and $240 \mathrm{bar})$ and nanoceria $(80 \mathrm{ppm})$ on the thermal behavior of a diesel engine running on biodiesel (B20). Better performance with lower emissions was observed for the cerium oxide nanoparticle-doped fuel at the highest injection pressure of 240 bar.

Sajith et al. (2010) also experimentally explored the impact of nanoceria as a fuel additive in Jatropha biodiesel. They reported that, at full load, the BTE using nanoparticle-dispersed biofuel was higher than that using neat biodiesel. Also, the $\mathrm{CeO}_{2}$ nanoparticle-doped fuel formulation exhibited lower $\mathrm{NO}_{\mathrm{X}}$ concentrations $\left(\mathrm{X}_{\mathrm{NO}}\right)$. Similarly, Mirzajanzadeh et al. (2015) also argued that the combustion of cerium oxide nanoparticle-blended fuel (diesel/waste cooking oil (WCO) biodiesel/ $/ \mathrm{CeO}_{2}(40-50 \mathrm{~nm})$ nanoparticles) led to considerable mitigation of $\mathrm{NO}_{\mathrm{x}}$ emissions. The authors used different concentrations of the nanoadditive, i.e., 30,60 , and $90 \mathrm{ppm}$, and recorded the maximum reduction in $\mathrm{X}_{\mathrm{NOx}}$ of $18.9 \%$ for the highest $\mathrm{CeO}_{2}$ nanoparticles concentration of $90 \mathrm{ppm}$. Selvan et al. (2009) also claimed a 54\% reduction in $\mathrm{X}_{\mathrm{NOx}}$ when the investigated diesel engine was operated with fuel formulations harboring $\mathrm{CeO}_{2}$ nanoparticles. Table 1 summarizes the results reported by the latest studies on the performance and emission characteristics of diesel engines powered by diesel/biodiesel blends carrying nanoceria as a fuel additive.

The performance of an engine operating with diesel and biodiesel fuel blends containing nanoadditives could be strongly influenced by biodiesel type and the different features of the nanoparticles used as an additive (type, size, morphology, oxide layer thickness, and volume fraction). The effects of various biodiesel types and variations in nanoparticle volume concentrations have been widely investigated. However, little is known about the impact of nanoparticle size on engine performance and emission characteristics. In light of that, this work aims to bridge this knowledge gap by investigating the performance and emission characteristics of a diesel engine powered with a biodiesel/diesel fuel blend (B20; WCO biodiesel) harboring $\mathrm{CeO}_{2}$ nanoparticles of varying sizes $(10,30$, and $80 \mathrm{~nm})$. Performance parameters (including brake specific energy consumption (BSEC), peak cylinder pressure, and heat release rate) and engine tailpipe gas emissions (including $\mathrm{X}_{\mathrm{CO}}, \mathrm{X}_{\mathrm{HC}}, \mathrm{X}_{\mathrm{NOx}}$, and smoke opacity) were measured and analyzed.

\section{Background: role of $\mathrm{CeO}_{2}$ nanoparticle catalyst in engine combustion}

Ceria is a naturally occurring rare earth element with two valence states, +3 and +4 . Ceria in +4 state is a non-trivalent rare-earth ion and a potent oxidizing agent. Ceria in +3 state resembles other trivalent rare earth elements. Ceria is widely used in the form of $\mathrm{CeO}_{2}$. It is a highly stable, non-toxic refractory material that melts at $2600{ }^{\circ} \mathrm{C}$ and has a density of 7.13 $\mathrm{g} / \mathrm{cm}^{3}$. It adopts the fluorite crystal structure with space group Fm3m, \#225 containing 8-coordinate $\mathrm{Ce}^{4+}$ and 4-coordinate $\mathrm{O}^{2-}$. The face-centered cubic (FCC) structure of stoichiometric cerium oxide, with four coordinated oxygen anions represented by large red balls and eight coordinated cerium cations represented by small blue balls, is shown in Figure 1 (Malavasi et al., 2010).

At high temperatures, cerium oxide discharges oxygen to provide an anion deficient form that maintains the fluorite lattice. Cerium oxide is widely used in catalysis, polishing, optics, mixed conduction, fuel cells, and engine applications (Mehrizi et al., 2018). Since the transformation from a +4 valence state to a +3 valence state is a low energy reaction, $\mathrm{CeO}_{2}$ is widely used as a catalyst in combustion reactions. Oxygen storage tendency of $\mathrm{CeO}_{2}$ during the catalysis process is shown in Equation 1 (Kaspar et al., 2000):

$2 \mathrm{CeO}_{2} \rightarrow \mathrm{Ce}_{2} \mathrm{O}_{3}+0.5 \mathrm{O}_{2}$

When $\mathrm{CeO}_{2}$ nanoparticles are added to a hydrocarbon-based fuel such as diesel and biodiesel, the inherent properties of $\mathrm{CeO}_{2}$ help reduce the hydrocarbon content and oxidize the soot particles, according to Equations 2 and 3 , respectively.

$(2 \mathrm{x}+\mathrm{y}) \mathrm{C}_{\mathrm{e}} \mathrm{O}_{2}+\mathrm{C}_{\mathrm{x}} \mathrm{H}_{\mathrm{y}} \rightarrow\left[\frac{(2 \mathrm{x}+\mathrm{y})}{2}\right] \mathrm{Ce}_{2} \mathrm{O}_{3}+\frac{\mathrm{x}}{2} \mathrm{CO}_{2}+\frac{\mathrm{y}}{2} \mathrm{H}_{2} \mathrm{O}$

$4 \mathrm{CeO}_{2}+\mathrm{C}_{\text {soot }} \rightarrow 2 \mathrm{Ce}_{2} \mathrm{O}_{3}+\mathrm{CO}_{2}$

$\mathrm{CeO}_{2}$ has a tendency to reduce $\mathrm{NO}_{\mathrm{X}}$ emissions. Initially, it reacts with hydrocarbons, forming cerous oxide $\left(\mathrm{Ce}_{2} \mathrm{O}_{3}\right)$. When $\mathrm{Ce}_{2} \mathrm{O}_{3}$ combines with oxides of nitrogen, the oxidation reaction takes place and it is re-oxidized to $\mathrm{CeO}_{2}$. The formation of nitrogen from $\mathrm{NO}_{\mathrm{X}}$ is presented in Equation 4 .

$\mathrm{Ce}_{2} \mathrm{O}_{3}+\mathrm{NO} \rightarrow 2 \mathrm{Ce}_{2} \mathrm{O}_{2}+\frac{1}{2} \mathrm{~N}_{2}$

Eq. 4

In addition to the catalytic property of $\mathrm{CeO}_{2}$, another significant advantage of this compound is its outstanding thermal conductivity making it suitable for use in heat transfer applications. The heat transmission rate of the nanoparticles directly relates to the conductivity of the nanofluid.

Table 1.

Main Summary of the findings of the latest studies on the application of nanoceria in various diesel/biodiesel blends.

\begin{tabular}{|c|c|c|}
\hline Fuel formulation & Main results & Ref. \\
\hline $\mathrm{Neem}$ oil biodiesel + diethyl ether $+\mathrm{CeO}_{2}$ nanoparticles & Combination of B10+150 ppm nanoadditive led to improved BTE with decreased emissions & Kapoor et al. (2020) \\
\hline Lemongrass biofuel $+30 \mathrm{ppm} \mathrm{CeO}_{2}$ & $\begin{array}{l}\text { BTE was increased by } 17.2 \% \text { with lower engine emissions for the fuel formulation harboring } \\
\text { nanoparticles }\end{array}$ & Venkatesan et al. (2019) \\
\hline Algae biodiesel $+25,50,75$, and $100 \mathrm{ppm} \mathrm{CeO}_{2}$ & B20 with 100 ppm nanoparticles showed maximum BTE & Kalaimurugan et al. (2020) \\
\hline Biodiesel $+50,100$, and $150 \mathrm{ppm}$ of $\mathrm{CeO}_{2}$ & Improved performance and reduced emissions for $\mathrm{B} 20+150 \mathrm{ppm}$ nanoceria & Kumar et al. (2020) \\
\hline WCO biodiesel $+\mathrm{Fe}$-doped $\mathrm{CeO}_{2}$ & $\begin{array}{l}\text { Peak cylinder pressure was increased by } 3.5 \% \text {, and } \mathrm{X}_{\mathrm{NO}_{x}} \text { was reduced by } 7 \% \text { for } \mathrm{B} 30 \text { doped with } \\
\mathrm{FeCeO}_{2} \text { nanoparticles }\end{array}$ & Hawi et al. (2019) \\
\hline $\begin{array}{l}\text { Waste cookinh oil }(\mathrm{WCO}) \text { biodiesel }+\mathrm{CeO}_{2} \\
\text { nanoparticles }+ \text { cerium composite oxide }\end{array}$ & $\begin{array}{l}\text { Fuel blend containing } \mathrm{CeO}_{2} \text { nanoparticles }+ \text { cerium composite oxide led to lower engine emissions with } \\
\text { better performance }\end{array}$ & Akram et al. (2019) \\
\hline Pongamia biodiesel $+\mathrm{CeO}_{2}$ and $\mathrm{CeO}_{2} \mathrm{Gd}$ & Reduced $\mathrm{X}_{\mathrm{CO}}$ and smoke opacity were obtained for biodiesel harboring $\mathrm{CeO}_{2} \mathrm{Gd}$ nanoparticles & Dhanasekar et al. (2019) \\
\hline Cinnanon oil + diesel $+\mathrm{CeO}_{2}$ nanoparticles & Reduced $\mathrm{XNO}_{\mathrm{x}}$ and $\mathrm{X}_{\mathrm{CO}}$ emissions were obtained for $\mathrm{B} 30$ containing $300 \mathrm{ppm} \mathrm{CeO}$ nanoparticles & Senthil Kumar et al. (2019) \\
\hline Mahua biodiesel +50 and $100 \mathrm{ppm} \mathrm{CeO}_{2}$ & $\begin{array}{l}\text { BTE was increased by } 1.8 \% \text {, while } \mathrm{X}_{\mathrm{CO}} \text { and } \mathrm{X}_{\mathrm{HC}} \text { were reduced for } \mathrm{B} 20 \text { doped with } 100 \mathrm{ppm} \mathrm{CeO}_{2} \\
\text { nanoparticles }\end{array}$ & Seela et al. (2019) \\
\hline
\end{tabular}




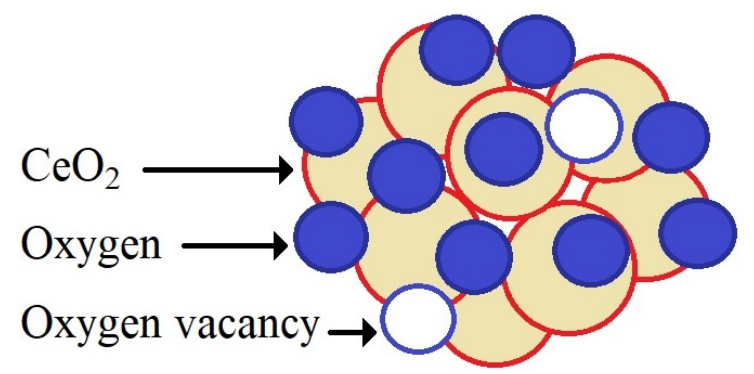

Fig. 1. Fluorite structure of $\mathrm{CeO}_{2}$.

When the nanoparticles are distributed in a base fluid such as biodiesel, the effective heat conductivity is enhanced. Furthermore, the size of the nanoparticles has a strong influence on the thermal conductivity of the nanofluid. Assuming $\mathrm{CeO}_{2}$ nanoparticles to be spherical in shape, the ratio of thermal conductivity of the nanofluid to the base fluid (neat B20) can be calculated using Equation 5 (Patel et al., 2010).

$\frac{\mathrm{K}_{\mathrm{nf}}}{\mathrm{K}_{\mathrm{f}}}=\left[1+0.135 \times\left(\frac{\mathrm{K}_{\mathrm{p}}}{\mathrm{K}_{\mathrm{f}}}\right)^{0.273} \times \varepsilon^{0.467} \times\left(\frac{\mathrm{T}}{20}\right)^{0.547} \times\left(\frac{100}{\mathrm{D}_{\mathrm{p}}}\right)^{0.234}\right]$

where, $\mathrm{K}_{\mathrm{nf}}, \mathrm{K}_{\mathrm{f}}$ and $\mathrm{K}_{\mathrm{p}}$ are the thermal conductivities (W/mK) of the nanofluid, the base fluid, and the nanoparticles, respectively. $\varepsilon$ is the volume fraction of the nanoparticle $(\%)$, $\mathrm{T}$ stands for the operating temperature $\left({ }^{\circ} \mathrm{C}\right)$, and $\mathrm{D}_{\mathrm{p}}$ denotes the nanoparticle size $(\mathrm{nm})$.

Equation 5 takes into account the size of the particle, its volume concentration, and temperature. Figure 2 depicts changes in the thermal conductivity of a nanofluid $v s$. changes in the volume fraction of several sizes of nanoparticles, as calculated using Equation 5. It is observed that $\mathrm{K}_{\mathrm{nf}}$ increases as the volume fraction is increased. Also, when the particle size is increased, $K_{n f}$ decreases. The increase in the specific surface area and enhanced Brownian motion of the particles might be the reasons to the higher $\mathrm{K}_{\mathrm{nf}}$ for smaller particle sizes. A smaller size particle has a more excellent surface-tovolume ratio, which in turn augments heat transfer to the base fluid. In addition, a small particle possesses higher Brownian motion velocity, which causes the heat transfer to occur at a faster rate. All these effects contribute to increasing the effective thermal conductivity and, correspondingly, to the heat transfer rate of the nanofluid (Iyahraja and Rajadurai, 2015).

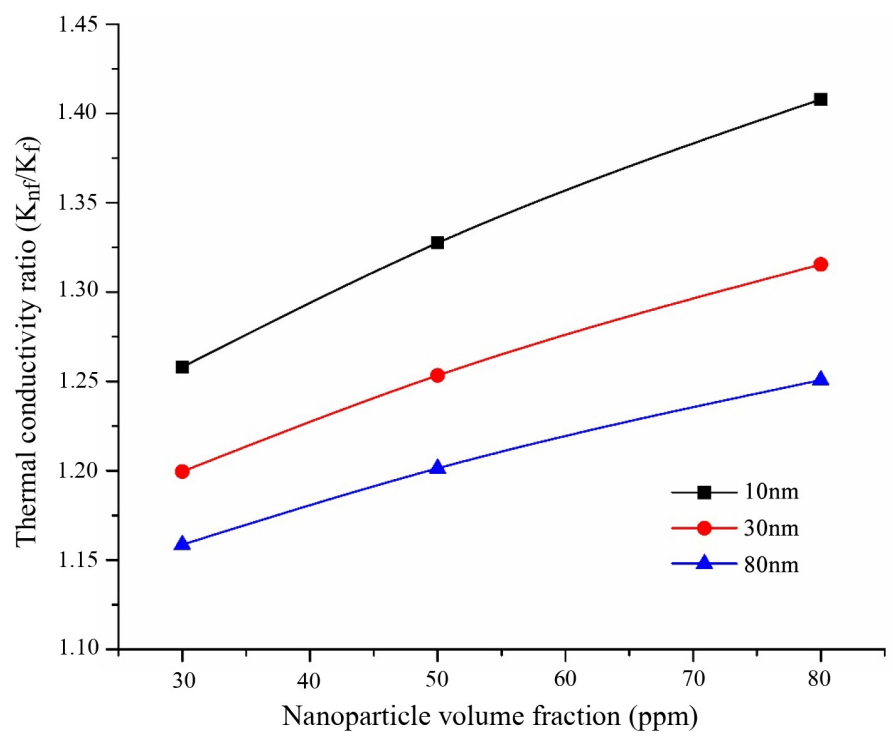

Fig. 2. Effect of size and concentration of cerium oxide on thermal conductivity of a nanofluid as calculated using Equation 5.

\section{Materials and Methods}

\subsection{Fuel blend preparation}

Esterified WCO biodiesel was procured from a local supplier. The physiochemical properties of neat WCO biodiesel complied with the American Society for Testing and Materials (ASTM) standard and those of B20 (20\% biodiesel and $80 \%$ diesel) and listed in Table 2. Three sizes of cerium oxide nanoparticle ( $v i z .10,30$, and $80 \mathrm{~nm}$ ) were used to prepare the test fuels. The concentration of the nanoparticles was kept constant at 80 ppm. The fuel formulations were designated as B20+10nm, B20+30nm, and $B 20+80 \mathrm{~nm}$. A suitable surfactant was selected and used in the present work to have a uniform dispersion of cerium oxide nanoparticles in investigated fuel blends. The choice of a surfactant would depend on the hydrophilic-lipophilic balance (HLB) of the surfactant, and in this case, it had to be soluble in the B20. Having screened various surfactants, dodecenylsuccinic anhydride (DDSA- $\mathrm{C}_{16} \mathrm{H}_{28} \mathrm{O}_{3}$ ), having a HLB value of 1.34 (Sajeevan and Sajith, 2013), was selected. The test fuel blends were processed by ultra-sonification for $0.5 \mathrm{~h}$ until $\mathrm{CeO}_{2}$ nanoparticles were well distributed in the fuel blends.

Table 2.

Physicochemical properties of B20 WCO biodiesel.

\begin{tabular}{lc}
\hline Property & Value \\
\hline Flash point $\left({ }^{\circ} \mathrm{C}\right)$ & 66 \\
Fire point $\left({ }^{\circ} \mathrm{C}\right)$ & 73 \\
Calorific value $(\mathrm{MJ} / \mathrm{kg})$ & 40.3 \\
Kinematic viscosity $(\mathrm{cSt})$ & 3.7 \\
Density $\left(\mathrm{kg} / \mathrm{m}^{3}\right)$ & 843 \\
\hline
\end{tabular}

\subsection{Test setup and experimentation}

The experiments were conducted on a Kirloskar TV1 four-stroke engine. It consisted of a single-cylinder with a water-cooled facility. Specifications of the engine are shown in Table 3. Figure 3 depicts a schematic presentation of the engine setup used in the present study. An eddy current type dynamometer was used for loading, and sensors are attached to determine temperatures. The cooling water flow rate of the engine jacket was measured using a rotameter. A computer connected to the setup generated pressure vs. crank angle plots from the signals. Fuel flow measurement was taken using a burette. An AVL exhaust gas analyzer and an AVL smoke meter were used to quantify emissions data. The range and resolution of the instruments used in the experiments are provided in Table 4.

Table 3.

Specifications of diesel engine.

\begin{tabular}{lc}
\hline Specification & Value/description \\
\hline Bore diameter $(\mathrm{mm})$ & 87.5 \\
Stroke length $(\mathrm{mm})$ & 110 \\
Compression ratio & $17.5: 1$ \\
Rated brake power $(\mathrm{kW})$ & 5.2 at a constant speed of $1500 \mathrm{rpm}$ \\
Normal Injection pressure (bar) & 180 \\
Swept volume $\left(\mathrm{cm}^{3}\right)$ & 661 \\
\hline
\end{tabular}

Table 4.

Range and resolution of the instruments.

\begin{tabular}{lcc}
\hline Item & Range & Resolution \\
\hline Pressure (bar) & $0.344-75$ & 0.0069 \\
Smoke opacity & $0-100$ & 0.01 \\
$\mathrm{NO}_{\mathrm{x} \text { concentration (ppm) }}$ & $0-5000$ & 1 \\
$\mathrm{CO}$ concentration (vol) & $0-10 \%$ & $0.01 \%$ \\
$\mathrm{HC}$ concentration (ppm) & $0-20,000$ & 10 \\
$\mathrm{CO}_{2}$ concentration (vol) & $0-20 \%$ & $0.1 \%$ \\
\hline
\end{tabular}




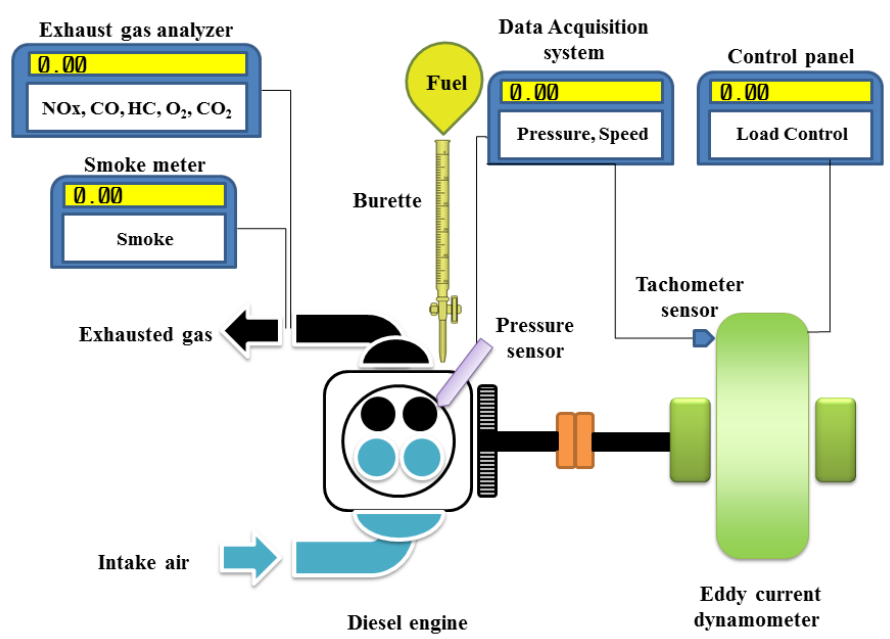

Fig. 3. Schematic representation of the engine setup.

\subsection{Heat release rate}

The instantaneous rate of heat release during burning was determined by Equation 6 (Heywood, 2018).

$\frac{d Q_{N}}{d \theta}=\frac{\gamma}{\gamma-1} p \frac{d V}{d \theta}+\frac{1}{\gamma-1} V \frac{d p}{d \theta}$

where $\mathrm{dQ}_{\mathrm{N}} / \mathrm{d} \theta$ denotes instantaneous heat release rate per degree crank angle ( $\mathrm{J} /$ degree), $\gamma$ ratio of specific heats, $\mathrm{p}$ cylinder pressure (bar), $\mathrm{V}$ cylinder volume $\left(\mathrm{m}^{3}\right)$, and $\Theta$ crank angle in degree, while $\mathrm{dV} / \mathrm{d} \Theta$ and $\mathrm{dp} / \mathrm{d} \Theta$ stand for instantaneous change in the cylinder volume and pressure per degree crank angle, respectively.

\subsection{Uncertainty analysis}

In laboratory experiments, uncertainty analysis deals with evaluating the uncertainty in any measurements. It allows estimation of the numerical value of a physical variable and how it is affected by errors due to instrumentation. In the present work, the uncertainty of a dependent variable was calculated using errors involved in measuring independent parameters such as load, speed, and fuel flow rate, using Equation 7.

$\mathrm{W}_{\mathrm{R}}=\left(\left[\frac{\partial \mathrm{R}}{\partial \mathrm{x}_{1}} \mathrm{~W}_{1}\right]^{2}+\left[\frac{\partial \mathrm{R}}{\partial \mathrm{x}_{2}} \mathrm{~W}_{2}\right]^{2}+\ldots .+\left[\frac{\partial \mathrm{R}}{\partial \mathrm{x}_{\mathrm{n}}} \mathrm{W}_{\mathrm{n}}\right]^{2}\right)^{1 / 2}$ 5.

The calculated uncertainty values for various parameters are listed in Table

Table 5.

Uncertainty analysis of selected measured parameters used in the study.

\begin{tabular}{lc}
\hline Measured quantity & Percentage uncertainty \\
\hline Load & 0.65 \\
Speed & 0.51 \\
Fuel flow rate & 0.8 \\
Brake specific fuel consumption & 1.4 \\
X $_{\text {NO }}$ & 2.0 \\
X $_{\text {HC }}$ & 2.1 \\
X $_{\text {CO }}$ & 1.4 \\
Smoke opacity & 0.65 \\
\hline
\end{tabular}

\section{Results and Discussion}

Test trials were conducted for several sizes of cerium oxide nanoparticles with a constant volume fraction of $80 \mathrm{ppm}$. Engine performance parameters, i.e., BSEC, peak cylinder pressure, and heat release rate, and tailpipe emissions, i.e., $\mathrm{X}_{\mathrm{NOx}}, \mathrm{X}_{\mathrm{CO}}, \mathrm{X}_{\mathrm{HC}}$, and smoke opacity for the investigated fuel formulations $(B 20+10 \mathrm{~nm}, \mathrm{~B} 20+30 \mathrm{~nm}$, and B20+80nm) and neat B20 as baseline are presented in the following subsections.

\section{1. $\mathrm{CeO}_{2}$ nanoparticles as a combustion promoter \\ 4.1.1. Cylinder peak pressure and heat release rate}

Cylinder peak pressure is an indication of combustion efficiency. If the fuel mixture undergoes complete combustion in the premixed phase, a higher cylinder pressure can usually be attained. This also results in increased power output with reduced emissions. From the data depicted in Figure 4, it can be observed that the cylinder peak pressure obtained with $\mathrm{CeO}_{2}$ nanoparticles-doped fuels was greater than that of additive-free B20. When $\mathrm{CeO}_{2}$ nanoparticles were added to the $\mathrm{B} 20$ fuel blend, they must have acted as heat carrier media, promoting heat flow among the fuel droplets and air. This phenomenon must have caused faster evaporation of the fuel droplets, reducing the delay period. Therefore, the autoignition temperature was attained faster relative to additive-free B20. These factors contributed to smooth combustion and the attainment of a higher cylinder peak pressure close to the top dead center (TDC). Among the different fuel formulations, the one containing $30 \mathrm{~nm}$ nanoparticles exhibited a higher peak pressure than the other two. When the particle size increases, the surface-to-volume ratio decreases, resulting in reduced heat transfer, as seen in the case of B20+80nm. This fuel formulation exhibited the lowest value of peak cylinder pressure among the three fuel variants (Fig. 4).

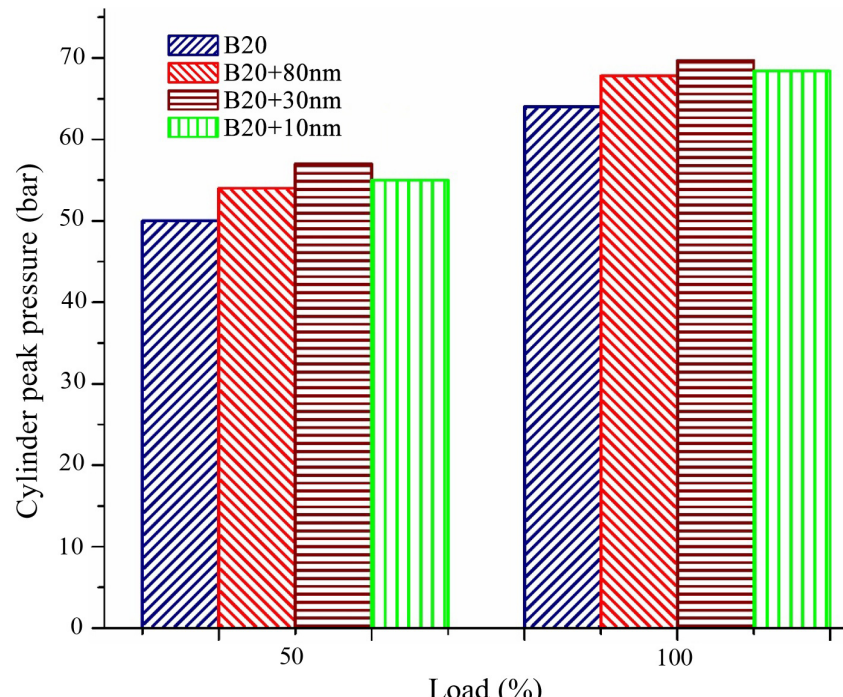

Load $(\%)$

Fig. 4. Variations of the cylinder peak pressure for different fuel formulations at part and full loads.

However, it should also be noted that when the particle size is too small, despite the higher surface-to-volume ratio, the transport characteristics of the fuel particles decrease due to reduced density. This in turn could result in poor mixing of the air and fuel as a local stoichiometric mixture. Also, the agglomeration tendency would be higher for too small particles. Hence, for the $\mathrm{B} 20+10 \mathrm{~nm}$ fuel blend, the peak pressure attained was moderate, whereas it was the largest for the $\mathrm{B} 20+30 \mathrm{~nm}$ fuel blend. Therefore, nanoparticle size of $30 \mathrm{~nm}$ could be regarded as optimum, exhibiting better combustion characteristics compared to the other nanoparticle sizes tested.

Figure 5 shows the net heat liberation rate for the fuels tested at full load conditions. The heat liberation rate is a function of the rate of pressure rise 
in the cylinder, as shown in Equation 6. Generally, when the peak cylinder pressure is higher, the rate of pressure rise is considerably higher. The higher rate of pressure rise is possible due to the better combustion achieved during the initial phase of combustion (i.e., premixed phase). The combined influence of a superior heat transfer mechanism and the catalytic action of $\mathrm{CeO}_{2}$ nanoparticles must have played a major role in achieving a more significant cylinder pressure rise and hence, a greater heat release rate (Fig. 5). The catalytic action of $\mathrm{CeO}_{2}$ oxidizes any unburnt hydrocarbon (UHC) and carbon monoxide present to $\mathrm{CO}_{2}$, liberating energy. This accounts for the total heat released during combustion. Compared to the baseline B20, the nanoparticlesdoped fuel formulations exhibited greater heat release rates, with B20+30nm ranked as the highest. The reasons for these observations could be the better fluid transport and thermal characteristics of $30 \mathrm{~nm}$-sized nanoparticles, as previously discussed on the cylinder peak pressure.

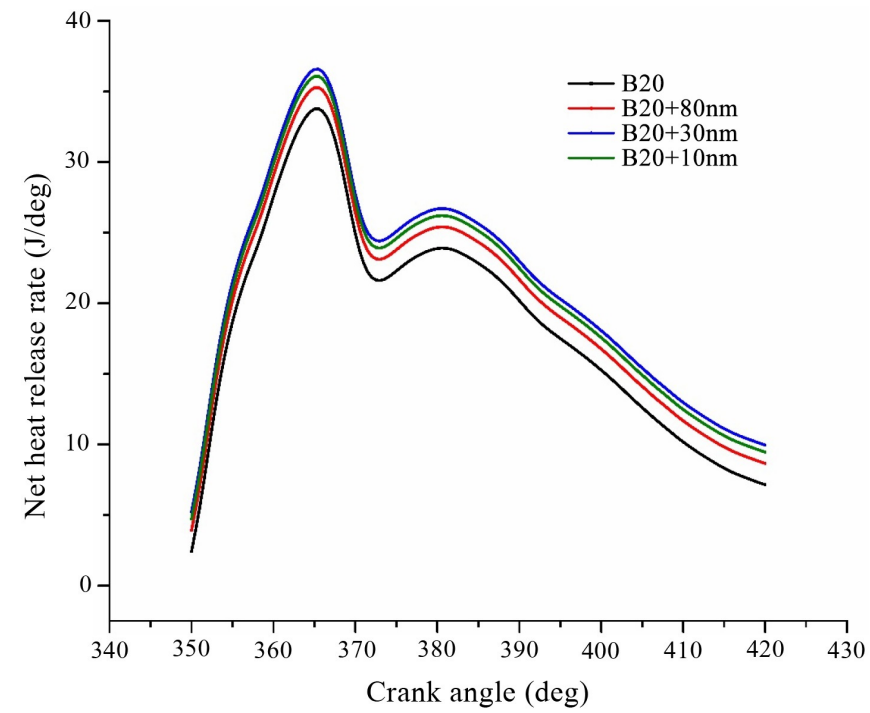

Fig. 5. Variations of net heat release rate for different fuel formulations $v s$. crank angle at full load.

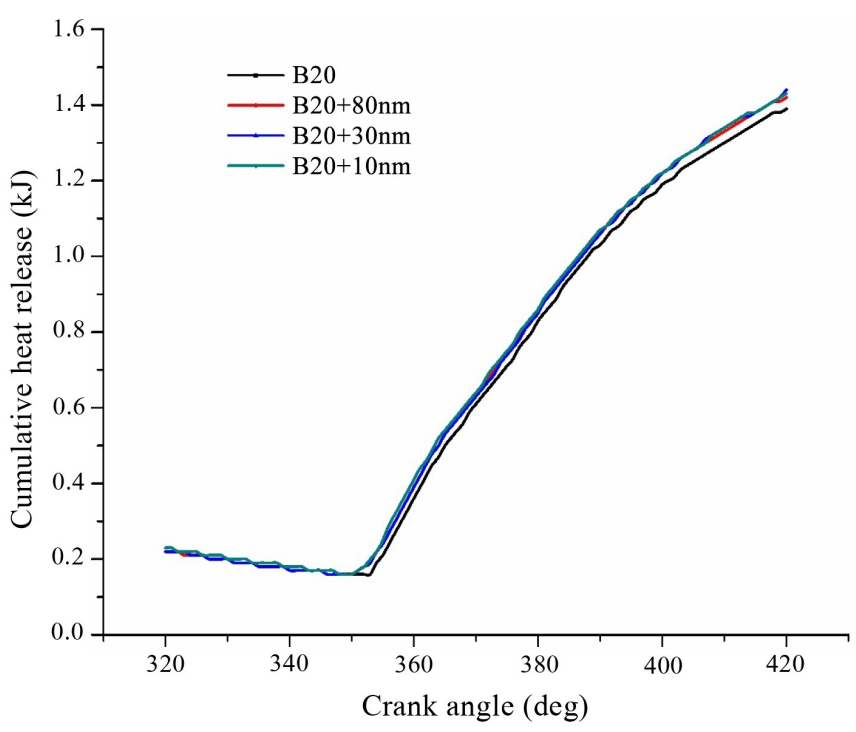

Fig. 6. Variations of cumulative heat release for different fuel formulations $v s$. crank angle at full load.

The cumulative heat release for each of the fuel blends tested is shown in Figure 6. These data reveal the overall heat release during fuel burning, which is the sum of heat liberated during premixed and diffused combustion phases.
The cumulative heat release is dependent on several factors such as the start and end of combustion, fuel nature and quality, and rate of pressure rise in the cylinder. The presence of $\mathrm{CeO}_{2}$ nanoparticles acted as a combustion promoter leading to the conversion of $\mathrm{CO}$ and $\mathrm{UHC}$ to $\mathrm{CO}_{2}$ by catalytic oxidation. This resulted in the release of additional energy, which would have been otherwise left as unburnt fuel in the exhaust. This additional energy increased the cumulative heat release during combustion, increasing the power output correspondingly. A comparison of the three test fuel formulations in Figure 6 indicates that $B 20+30 \mathrm{~nm}$ had the highest cumulative heat release.

\subsubsection{Brake specific fuel consumption}

In general, brake specific fuel consumption (BSEC) represents the energy consumption per unit specific engine output (brake power). BSEC is higher at part load operation and gradually decreases as the load is increased until reaching a minimum at $70-80 \%$ of the full of the engine (Mathur and Sharma, 2011). From the data presented in Figure 7, it can be seen that the BSEC for all nanoparticles-doped fuel formulations was lower than for additive-free $\mathrm{B} 20$. When $\mathrm{CeO}_{2}$ nanoparticles were doped to the biodiesel blend, a better quality of fuel preparation took place, leading to a more favorable heat flow among the air and fuel droplets. This must have helped with decreasing the ignition delay and improved combustion. These factors likely contributed to reducing BSEC by the effective utilization of the injected fuel. These results are consistent with those reported in the literature previously. For instance, Hawi et al. (2019) observed a lower BSFC for B30 containing iron-doped $\mathrm{CeO}_{2}$ nanoparticles for low to medium loads. At high loads, BSFC was comparable to the results for diesel fuel. Also, Mirzajanzadeh et al. (2015) reported a 4.5\% reduction of BSEC for B20 harboring $90 \mathrm{ppm}$ of carbon nanotubes and $\mathrm{CeO}_{2}$ nanoparticles, compared to the corresponding values recorded for the additive-free fuel blend.

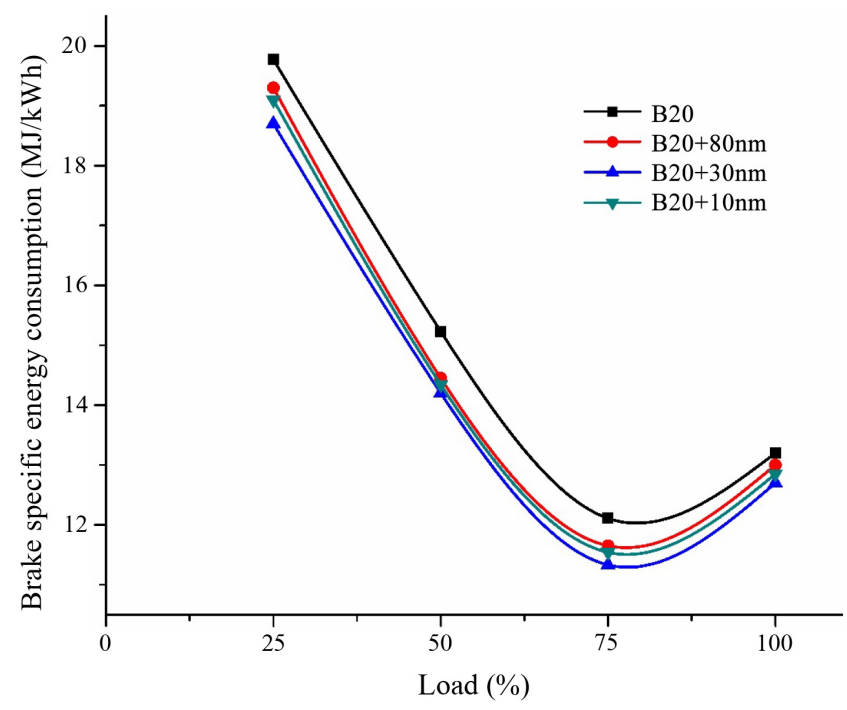

Fig. 7. Variations of brake specific fuel consumption (BSEC) for the different fuel formulations against engine load.

Based on the results of the present study, particle size seems to exert a significant effect on fuel consumption. Among the investigated fuel formulation, B20+30nm and B20+80nm were at the extremes, with the former exhibiting minimum BSEC and the latter the maximum. It could be concluded that, in general, BSEC decreased as the nanoparticle size was reduced. As discussed earlier, the surface-to-volume ratio increases for smaller particle sizes, assisting with achieving uniformity in air-fuel mixing. This enhances the heat transfer rate, reducing ignition delay. Reduced ignition delay improves combustion, reducing BSEC. In the present study, the lowest BSEC was observed for an optimum nanoparticle 
size of $30 \mathrm{~nm}$. However, when the nanoparticle size was too small, the nanoparticle might not have traversed effectively to various regions in the combustion chamber due to lower density, resulting in non-uniform mixing. This might have increased the ignition delay, leading to poor combustion and consequently a slightly higher BSEC.

\subsection{Catalytic action of $\mathrm{CeO}_{2}$ and emission control}

Three essential properties are needed for a catalyst for being efficient in diesel engine combustion: (i) completing hydrocarbon oxidation, (ii) preventing the formation of oxides of nitrogen, and (iii) possessing high thermal stability. $\mathrm{CeO}_{2}$ can donate oxygen for the oxidation of hydrocarbons and soot. A unique feature of a $\mathrm{CeO}_{2}$ catalyst is that it activates at low temperature, generally $300-500{ }^{\circ} \mathrm{C}$, and can donate $\mathrm{O}_{2}$ for the oxidation reaction. In diesel engines, combustion takes place at high temperatures, the diesel flame front usually having a temperature of $1700^{\circ} \mathrm{C}$. At this elevated temperature, the formation of oxides of nitrogen during the chemical reactions between nitrogen and oxygen is likely. The $\mathrm{CeO}_{2}$ nanoparticles acted as a catalyst and promoted a more complete burning of the injected fuel. During the reduction of $\mathrm{NO}$ to $\mathrm{N}_{2}$, the average cylinder temperature reduces from approximately $1700{ }^{\circ} \mathrm{C}$ due to the high activation energy of nitrogen. This further helps to prevent the formation of oxides of nitrogen. In addition, the high thermal stability of $\mathrm{CeO}_{2}$ nanoparticles favors its catalytic activity. Once the initial combustion is achieved, $\mathrm{CeO}_{2}$ undergoes initial oxidation. This is because nanoceria is thermally stable and remains active after re-oxidation for further catalytic action. Hence, $\mathrm{CeO}_{2}$ nanoparticles undergo oxidation and reduction reactions, lowering the $\mathrm{X}_{\mathrm{CO}}, \mathrm{X}_{\mathrm{HC}}$, and $\mathrm{X}_{\mathrm{NOx}}$ and soot concentration as shown in Equations 2-4.

The catalytic activity of $\mathrm{CeO}_{2}$ is a strong function of its surface area. It has been observed that when the surface area of $\mathrm{CeO}_{2}$ nanoparticle increased by a factor of 20, the carbon combustion activation temperature decreased from 700 to $300{ }^{\circ} \mathrm{C}$ (Logothetid is et al., 2003). A higher surface area is obtained by reducing the nanoparticle size. Soot particles and UHC sticking to the combustion chamber walls are oxidized to $\mathrm{CO}_{2}$ when they come into contact with the nanoparticles, resulting in reduced tailpipe emissions and improved fuel economy. Hence better catalytic action is favored by small $\mathrm{CeO}_{2}$ nanoparticles.

\subsubsection{Hydrocarbon, carbon monoxide, and soot oxidation}

Figure 8 depicts the variations of $\mathrm{X}_{\mathrm{HC}}$ for the different fuel formulations at various engine load conditions. As the load increased, the $X_{\mathrm{HC}}$ also increased and higher values were observed at full load. $\mathrm{HC}$ emissions were lowest at part load conditions and increased rapidly during the full load operation. The $\mathrm{X}_{\mathrm{HC}}$ for additive-free B20 fuel was found to be the highest of all fuel blends. This can be attributed to the higher viscosity, reduced penetration, and dispersion leading to poor combustion. When nanoparticles were included, because of the catalytic action of $\mathrm{CeO}_{2}$ according to Equations 1-3, nanoceria could undergo a conversion from a stoichiometric $\mathrm{CeO}_{2}(+4)$ valence state to $\mathrm{Ce}_{2} \mathrm{O}_{3}(+3)$ state, through a comparatively low energy reaction. This means that cerium oxide gave oxygen for reducing UHC and was thereby converted to cerous oxide, $\mathrm{CO}_{2}$, and water (Mei et al., 2015). When diesel fuel was mixed with $\mathrm{CeO}_{2}$ nanoparticles, the $\mathrm{X}_{\mathrm{HC}}$ was reduced by $7 \%$ compared to neat diesel, similar to the result previously reported by Shaisundaram et al. (2020). Among the different particle sizes examined, B20+30nm exhibited the lowest $X_{\mathrm{HC}}$. Even though the surface area provided by $10 \mathrm{~nm}$-sized nanoparticles was higher, the agglomeration and the poor transport capability of the nanoparticles must have led to poor dispersion. This prevented the nanoparticles from reaching the regions where $\mathrm{CO}$ and $\mathrm{HC}$ formation taking place, resulting in poor combustion and a slight increase in $X_{\mathrm{HC}}$. Based on the results of the present study, $B 20+30 \mathrm{~nm}$ fuel formulation was associated with the most significant $X_{\mathrm{HC}}$ decline of $35 \%$ compared to the additive-free B20.

The main reason for $\mathrm{CO}$ formation is the shortage of oxygen for the oxidation reaction. When the carbon activation temperature is high, as in the typical diesel engine combustion, the complete transformation of $\mathrm{CO}$ to $\mathrm{CO}_{2}$ is complex. At the same time, it takes longer for the conversion process as the activation temperature is higher. $\mathrm{CeO}_{2}$, when added to the fuel, acts as a catalyst and reduces the carbon activation temperature. Hence, the oxidation of $\mathrm{CO}$ to $\mathrm{CO}_{2}$ can occur at low temperatures. Due to this phenomenon, a more complete conversion of $\mathrm{CO}$ to $\mathrm{CO}_{2}$ could take place, leading to reduced $\mathrm{X}_{\mathrm{CO}}$. Of the three

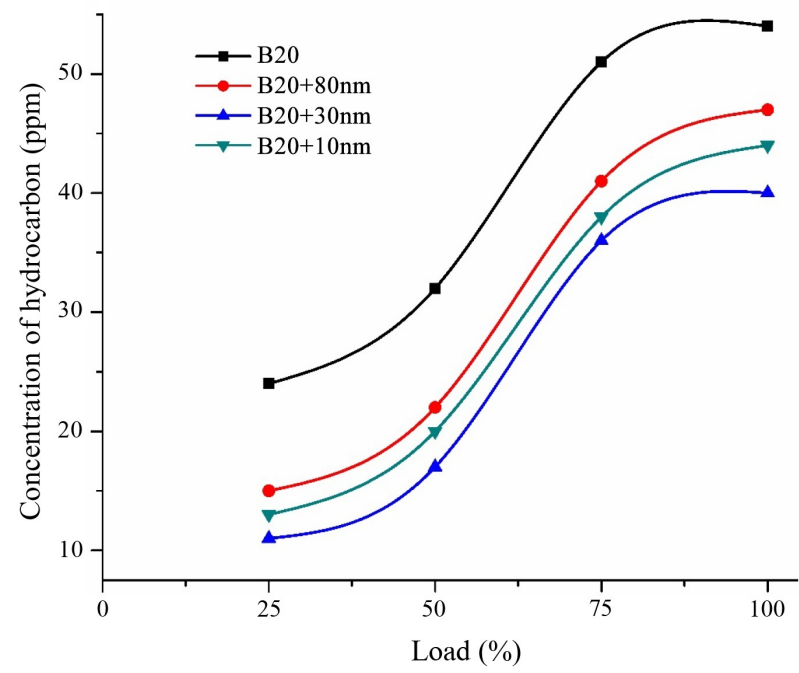

Fig. 8. Variations of $\mathrm{X}_{\mathrm{HC}}$ for the different fuel formulations against engine load.

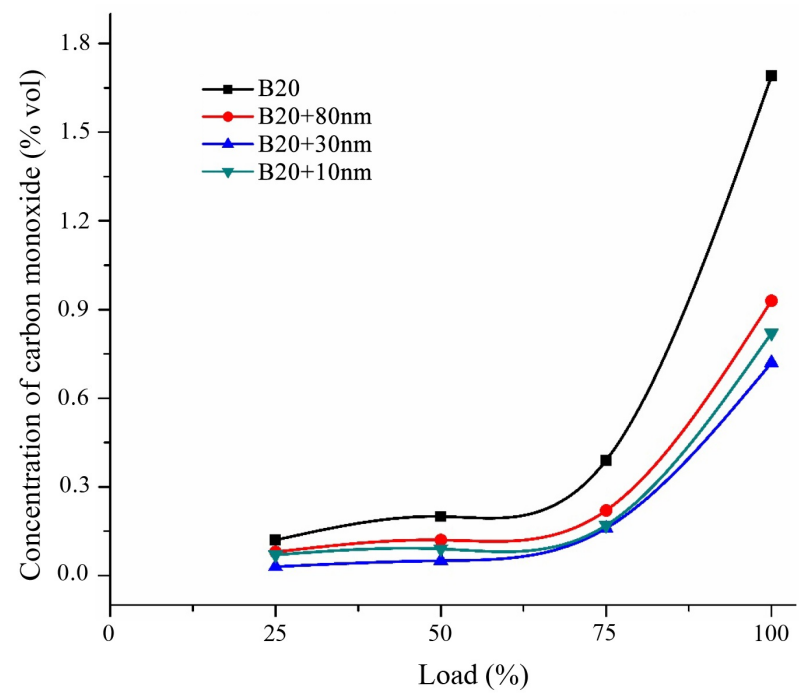

Fig. 9. Variations of $\mathrm{X}_{\mathrm{CO}}$ for the different fuel formulations against engine load

nanoparticles-doped fuel formulations, B20+30nm exhibits the lowest $\mathrm{X}_{\mathrm{CO}}$ value, whereas B20+80nm showed the highest, as shown in Figure 9. Nevertheless, these values were respectively $135 \%$ and $81 \%$ lower than the corresponding value recorded for additive-free B20 operation.

Smoke is comprised of unburnt carbon particles generated during the initial stage of combustion. The main reasons for soot formation are oxygen deficiency and the quenching action occurring near the cylinder wall Quenching results in the deposition of carbon particles at the wall surface, acting as a barrier for heat transfer. This increases frictional losses, reduces the power output, and consequently, increases fuel consumption. The addition of $\mathrm{CeO}_{2}$ nanoparticles plays a major catalytic role in decreasing soot formation. The carbon activation temperature drops due to the addition of $\mathrm{CeO}_{2}$ to around $200-500{ }^{\circ} \mathrm{C}$. This temperature is sufficient for the oxidation of soot particles to $\mathrm{CO}_{2}$, as shown in Equation 3. Hence, $\mathrm{CeO}_{2}$ reduces the formation of smoke and its emission. Appavu and Venkata Ramanan (2020) also reported reduced smoke opacity for 50 and 100 ppm $\mathrm{CeO}_{2}$ nanoparticle concentrations with Pongamia biodiesel. Seela et al. (2019) observed decreased smoke opacity by $8 \%$ when the $\mathrm{CeO}_{2}$ nanoparticles dosage was increased from 50 to $100 \mathrm{ppm}$. In the present study, of the three nanoparticle sizes considered, the fuel formulation harboring $30 \mathrm{~nm}$-nanoparticles, i.e., B20+30nm, had the lowest soot emission (Fig. 10). The observed value was 53\% less than the value measured for the additive-free B20 fuel operation. 


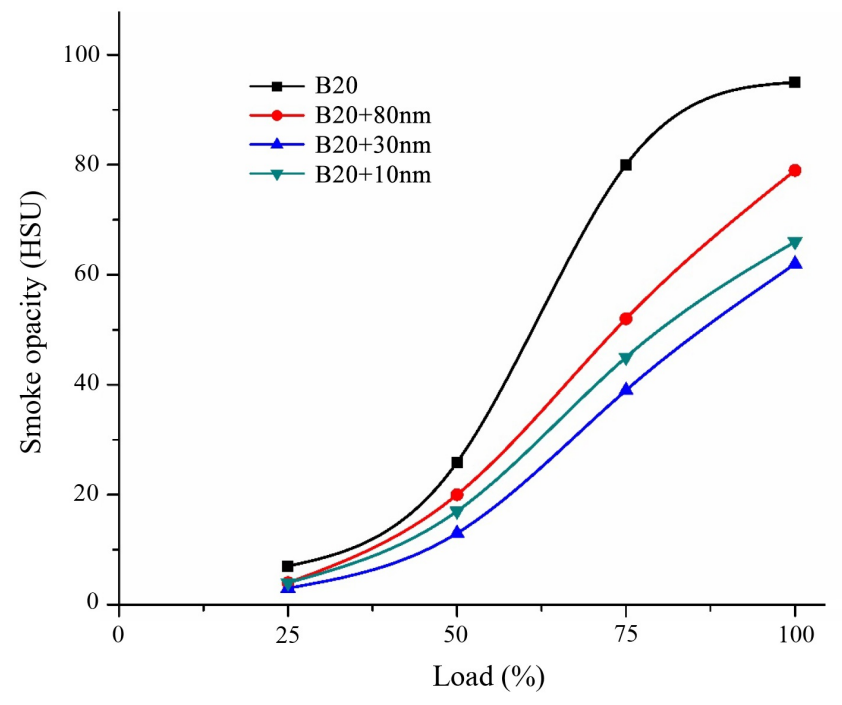

Fig. 10. Variations of smoke opacity for the different fuel formulations against engine load.

\subsubsection{Oxides of nitrogen}

The emission of oxides of nitrogen is a major drawback of biodiesel when used in diesel engines. NOx formation occurs due to excess oxygen, high combustion temperature, and the relatively long residence time. During biodiesel combustion, fuel-borne oxygen promotes the oxidation of $\mathrm{N}_{2}$. This is further enhanced by the higher combustion temperature prevailing in the combustion chamber. Several techniques are used to reduce $\mathrm{X}_{\mathrm{NOx}}$ in the tailpipe exhaust (Brijesh and Sreedhara, 2013). Although they reduce $\mathbf{X}_{\mathrm{NOx}}$, these techniques also increase the $\mathrm{X}_{\mathrm{HC}}$ and $\mathrm{X}_{\mathrm{CO}}$ or reduce the engine performance.

The use of $\mathrm{CeO}_{2}$ as a catalyst in engines is a novel technique to reduce $\mathrm{X}_{\mathrm{NOx}}$, simultaneously reducing other emissions without compromising engine performance or even slightly improving it. The catalytic activity of $\mathrm{CeO}_{2}$ on $\mathrm{X}_{\mathrm{NOx}}$ reduction can be explained by Equation 4, wherein $\mathrm{CeO}_{2}$ initially undergoes a reaction and forms $\mathrm{Ce}_{2} \mathrm{O}_{3}$. This is further reduced to $\mathrm{CeO}_{2}$ by combining with oxides of nitrogen, liberating nitrogen. During this process, $\mathrm{CeO}_{2}$ nanoparticles also help reduce the combustion temperature of the fuel-air mixture, as the activation energy of $\mathrm{N}_{2}$ is higher. Appavu and Venkata Ramanan (2020) also investigated diesel engine performance using Pongamia biodiesel with $\mathrm{CeO}_{2}$ nanoparticles. The authors observed reduced values of $\mathrm{X}_{\mathrm{NOx}}$ for $\mathrm{CeO}_{2}$-doped esters at all loads.

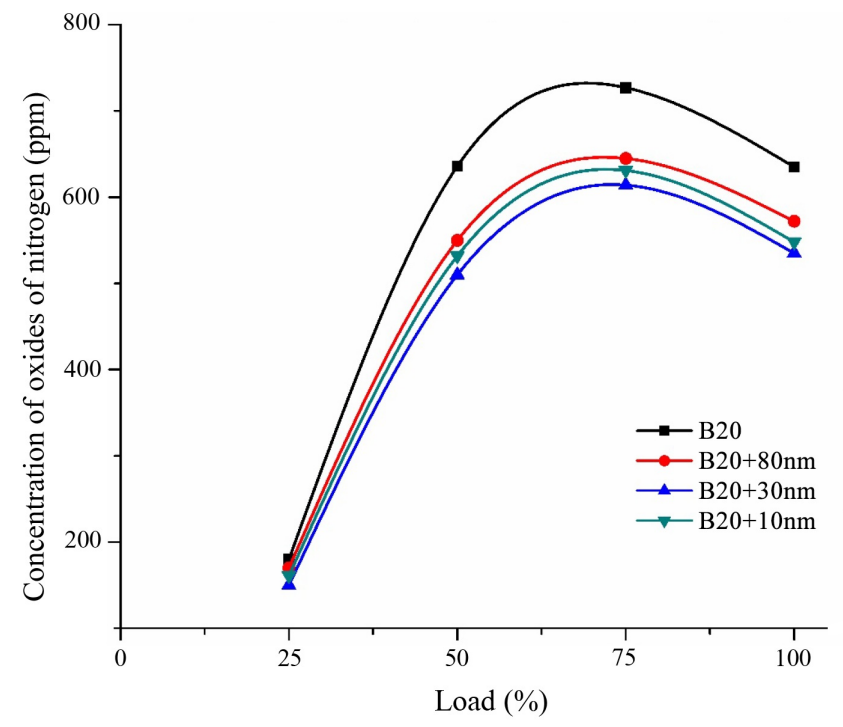

Fig. 11. Variations for $\mathrm{X}_{\mathrm{NOx}}$ for the different fuel formulations against engine load.
From the data presented in Figure 11, it can be observed that the combustion of the additive-free B20 led to the highest $X_{\text {NOx }}$ under all loading conditions. Among the fuel formulations harboring nanoparticles, $\mathrm{B} 20+30 \mathrm{~nm}$ exhibited the lowest $\mathrm{X}_{\mathrm{NO}}$ value, which was $7 \%$ less than the corresponding values recorded for $\mathrm{B} 20+10$ and $\mathrm{B} 20+80 \mathrm{~nm}$.

\section{Conclusions and future research directions}

Experiments were conducted to investigate the performance and emissions characteristics of different B20-based fuel formations harboring different sizes of $\mathrm{CeO}_{2}$ nanoparticles. Additive-free $\mathrm{B} 20$ was used as control. Based on the results obtained, the following conclusions could be drawn:

- $\mathrm{CeO}_{2}$ as a catalyst plays a major role in improving engine combustion, increasing BTE and reducing BSFC. The size of the nanoparticles had an instrumental effect on the variations recorded. The $30 \mathrm{~nm}$-sized nanoparticles led to the most significant decrease in BSEC, by $6.4 \%$ compared to the additive-free B20.

- The results revealed that the maximum values of heat release rate and cylinder peak pressure were also associated with the B20+30nm fuel formulation.

- The catalytic action of $\mathrm{CeO}_{2}$ reduced the carbon activation temperature, which helped oxidize the $\mathrm{HC}, \mathrm{CO}$, and soot present in the combustion chamber and the quenching regions to carbon dioxide, decreasing engine tailpipe emissions. Furthermore, the B20+30nm fue formulation resulted in the lowest emissions than the other fuel formulations harboring nanoparticles of smaller or larger sizes. This finding further signified the importance of the size of the fuel nanoadditives.

- $\mathrm{CeO}_{2}$ contributed to oxides of nitrogen undergoing oxidation-reduction reactions and hence, to their conversion to nitrogen, keeping $X_{\text {NOx }}$ at a relatively low value. Again, $30 \mathrm{~nm}$-sized nanoceria was found the most effective in decreasing $\mathrm{X}_{\mathrm{NOx}}$ compared with its $10 \mathrm{~nm}$ and $80 \mathrm{~nm}$-sized counterparts.

In general, it can be concluded that the addition of $\mathrm{CeO}_{2}$ effectively reduced engine emissions while simultaneously improving engine performance. In addition, the nanoparticle size determined the level of the catalytic action of $\mathrm{CeO}_{2}$ in engine combustion and emission control. These findings highlight the need for further works in this area. Those include but are not limited to optimizing fuel injection characteristics with nanoparticle additives for better engine performance and investigating the effects of two or more nanoparticles and size variations on engine combustion parameters. Moreover, sustainability analysis of various fuel formulations harboring nanoadditives of different sizes using advanced sustainability assessment tools such as life cycle assessment, exergy, and their combinations should be considered.

\section{References}

[1] Agarwal, A.K., 2007. Biofuels (alcohols and biodiesel) applications as fuels for internal combustion engines. Prog. Energy Combust. Sci. 33(3), 233-271

[2] Agarwal, D., Kumar, L., Agarwal, A.K., 2008. Performance evaluation of a vegetable oil fuelled compression ignition engine Renewable Energy. 33(6), 1147-1156

[3] Akram, S., Mumtaz, M.W., Danish, M., Mukhtar, H., Irfan, A., Raza, S.A., Wang, Z., Arshad, M., 2019. Impact of cerium oxide and cerium composite oxide as nano additives on the gaseous exhaust emission profile of waste cooking oil based biodiesel at full engine load conditions. Renewable Energy. 143, 898-905.

[4] Alptekin, E., 2017. Emission, injection and combustion characteristics of biodiesel and oxygenated fuel blends in a common rail diesel engine. Energy. 119, 44-52.

[5] An, H., Yang, W.M., Maghbouli, A., Li, J., Chou, S.K., Chua, K.J., 2013. Performance, combustion and emission characteristics of biodiesel derived from waste cooking oils. Appl. Energy. 112, 493- 
499.

[6] Appavu, P., Venkata Ramanan, M., 2020. Study of emission characteristics of a diesel engine using cerium oxide nanoparticle blended pongamia methyl ester. Int. J. Ambient Energy. 41(5), 524527.

[7] Bertola, A., Li, R., Boulouchos, K., 2003. Influence of water-diesel fuel emulsions and EGR on combustion and exhaust emissions of heavy duty DI-diesel engines equipped with common-rail injection system. SAE transactions. 2244-2260.

[8] Brijesh, P., Sreedhara, S., 2013. Exhaust emissions and its control methods in compression ignition engines: a review. Int. J. Automot. Technol. 14(2), 195-206.

[9] Dhanasekar, K., Sridaran, M., Arivanandhan, M., Jayavel, R., 2019. A facile preparation, performance and emission analysis of pongamia oil based novel biodiesel in diesel engine with $\mathrm{CeO}_{2}$ : $\mathrm{Gd}$ nanoparticles. Fuel. 255, 115756.

[10] Dinesha, P., Kumar, S., Rosen, M.A., 2019. Combined effects of water emulsion and diethyl ether additive on combustion performance and emissions of a compression ignition engine using biodiesel blends. Energy. 179, 928-937.

[11] D'Silva, R., Fernandes, N., Menezes, M., D'Souza, P., Pinto, V., Kaliveer, V., Gopalakrishna, B.K., Bhat, T., 2019. Effect of TiO2 nanoparticle concentration in Pongamia Pinnata methyl ester on performance and emission characteristics of $\mathrm{CI}$ engine. AIP Conf. Proc. 2080(1), 030006

[12] Hawi, M., Elwardany, A., Ismail, M., Ahmed, M., 2019. Experimental investigation on performance of a compression ignition engine fueled with waste cooking oil biodiesel-diesel blend enhanced with irondoped cerium oxide nanoparticles. Energies. 12(5), 798.

[13] Heywood, J.B., 2018. Internal combustion engine fundamentals, second ed. McGraw Hill, New York.

[14] Iyahraja, S., Rajadurai, J.S., 2015. Study of thermal conductivity enhancement of aqueous suspensions containing silver nanoparticles. AIP Adv. 5(5), 057103.

[15] Izquierdo, J.F., Montiel, M., Palés, I., Outón, P.R., Galán, M., Jutglar, L., Villarrubia, M., Izquierdo, M., Hermo, M.P., Ariza, X., 2012. Fuel additives from glycerol etherification with light olefins: state of the art. Renew. Sust. Energy Rev. 16(9), 6717-6724.

[16] Kalaimurugan, K., Karthikeyan, S., Periyasamy, M., Mahendran, G., 2020. Experimental investigations on the performance characteristics of CI engine fuelled with cerium oxide nanoparticle added biodieseldiesel blends. Mater. Today:. Proc. 33(7), 2882-2885.

[17] Kao, M.J., Ting, C.C., Lin, B.F., Tsung, T.T., 2007. Aqueous aluminum nanofluid combustion in diesel fuel. J. Test. Eval. 36(2), 186-190.

[18] Kapoor, M., Kumar, N., Verma, A.S., Gautam, G., Padap, A.K., 2020. Performance and emission analysis of compression ignition engine with neem methyl ester mixed with cerium oxide $\left(\mathrm{CeO}_{2}\right)$ nanoparticles. J. Energy Resour. Technol. 142(8), 082308.

[19] Kaspar, J., Graziani, M., Fornasiero, P., 2000. Chapter 184 ceriacontaining three-way catalysts. Handbook on the Physics and Chemistry of Rare Earths. 29, 159-267.

[20] Kumar, S., Dinesha, P., Bran, I., 2017. Influence of nanoparticles on the performance and emission characteristics of a biodiesel fuelled engine: an experimental analysis. Energy. 140, 98-105.

[21] Kumar, S., Dinesha, P., Gaggad, A., Mehrotra, K., 2018. Performance of an automotive car radiator operated with nanofluid-based coolant. Heat Transfer Res. 49(16)

[22] Kumar, S., Dinesha, P., 2019. Use of alternative fuels in compression ignition engines: a review. Biofuels. 10(4), 525-535.

[23] Kumar, S., Dinesha, P., Bran, I., 2019a. Experimental investigation of the effects of nanoparticles as an additive in diesel and biodiesel fuelled engines: a review. Biofuels. 10(5), 615-622.

[24] Kumar, S., Dinesha, P., Rosen, M.A., 2019b. Effect of injection pressure on the combustion, performance and emission characteristics of a biodiesel engine with cerium oxide nanoparticle additive. Energy. 185, 1163-1173.

[25] Kumar, S., Dinesha, P., Ajay, C.M., Kabbur, P., 2020. Combined effect of oxygenated liquid and metal oxide nanoparticle fuel additives on the combustion characteristics of a biodiesel engine operated with higher blend percentages. Energy. 197, 117194.

[26] Logothetidis, S., Patsalas, P., Charitidis, C., 2003. Enhanced catalytic activity of nanostructured cerium oxide films. Mate. Sci. Eng., C. 23(6-8), 803-806.

[27] Malavasi, L., Fisher, C.A., Islam, M.S., 2010. Oxide-ion and proton conducting electrolyte materials for clean energy applications: structural and mechanistic features. Chem. Soc. Rev. 39(11), 43704387.

[28] Mathur, M.L., Sharma, R.P., 2011. Internal Combustion Engines. Dhanpat Rai Publications, New Delhi.

[29] Mehrizi, M.Z., Ahmadi, S., Beygi, R., Asadi, M., 2018. Fabrication of cerium oxide nanoparticles by solution combustion synthesis and their cytotoxicity evaluation. Russ. J. Non-Ferrous Met. 59(1), 111 116.

[30] Mei, D., Li, X., Wu, Q., Sun, P., 2015. Role of cerium oxide nanoparticles as diesel additives in combustion efficiency improvements and emission reduction. J. Energy Eng. 142(4), 04015050

[31] Mirzajanzadeh, M., Tabatabaei, M., Ardjmand, M., Rashidi, A. Ghobadian, B., Barkhi, M., Pazouki, M., 2015. A novel soluble nano-catalysts in diesel-biodiesel fuel blends to improve diesel engines performance and reduce exhaust emissions. Fuel. 139, $374-$ 382.

[32] Muralidharan, K., Vasudevan, D., Sheeba, K.N., 2011 Performance, emission and combustion characteristics of biodiesel fuelled variable compression ratio engine. Energy. 36(8), 53855393.

[33] Patel, H.E., Sundararajan, T., Das, S.K., 2010. An experimental investigation into the thermal conductivity enhancement in oxide and metallic nanofluids. J. Nanoparticle Res. 12(3), 1015-1031.

[34] Prabu, A., 2018. Nanoparticles as additive in biodiesel on the working characteristics of a DI diesel engine. Ain Shams Eng. J. 9(4), 2343-2349

[35] Qi, D.H., Geng, L.M., Chen, H., Bian, Y.Z., Liu, J., Ren, X.C., 2009. Combustion and performance evaluation of a diesel engine fueled with biodiesel produced from soybean crude oil. Renew. Energy. 34(12), 2706-2713.

[36] Rakopoulos, C.D., Antonopoulos, K.A., Rakopoulos, D.C., Hountalas, D.T., Giakoumis, E.G., 2006. Comparative performance and emissions study of a direct injection diesel engine using blends of diesel fuel with vegetable oils or bio-diesels of various origins. Energy Convers. Manage. 47(18-19), 3272-3287.

[37] Ramesh, D.K., Kumar, J.D., Kumar, S.H., Namith, V., Jambagi, P.B., Sharath, S., 2018. Study on effects of alumina nanoparticles as additive with poultry litter biodiesel on performance, combustion and emission characteristic of diesel engine. Mater. Today:. Proc. $5(1), 1114-1120$

[38] Rao, D.S., Dash, R.K., 2015. Effect of nanomaterials sizes on the dispersion stability of biodiesel based nanofluids. Adv. Mater. Lett. 6(3), 247-251.

[39] Sajeevan, A.C., Sajith, V., 2013. Diesel engine emission reduction using catalytic nanoparticles: an experimental investigation. J. Eng. 2013, 589382.

[40] Sajith, V., Sobhan, C.B., Peterson, G.P., 2010. Experimental investigations on the effects of cerium oxide nanoparticle fuel additives on biodiesel. Adv. Mech. Eng. 2, 581407.

[41] Seela, C.R., Ravi Sankar, B., Kishore, D., Babu, M.V.S., 2019. Experimental analysis on a DI diesel engine with cerium-oxideadded Mahua methyl ester blends. Int. J. Ambient Energy 40(1) 49-53.

[42] Selvan, V.A.M., Anand, R.B., Udayakumar, M., 2009. Effects of cerium oxide nanoparticle addition in diesel and diesel-biodieselethanol blends on the performance and emission characteristics of a CI engine. ARPN J. Eng. Appl. Sci. 4(7), 1819-6608.

[43] Senthil Kumar, J., Ganesan, S., Raja, K.S., 2019. Experimental analysis of the effects of cerium oxide nanoparticles on a single- 
cylinder diesel engine using biofuel blended with diesel as fuel. Int. J. Ambient Energy. 40(5), 490-493.

[44] Shaisundaram, V.S., Chandrasekaran, M., Mohan Raj, S., Muraliraja, R., 2020. Investigation on the effect of thermal barrier coating at different dosing levels of cerium oxide nanoparticle fuel on diesel in a CI engine. Int. J. Ambient Energy. 41(1), 98-104.

[45] Sureshkumar, K., Velraj, R., Ganesan, R., 2008. Performance and exhaust emission characteristics of a CI engine fueled with Pongamia pinnata methyl ester (PPME) and its blends with diesel. Renewable Energy. 33(10), 2294-2302.

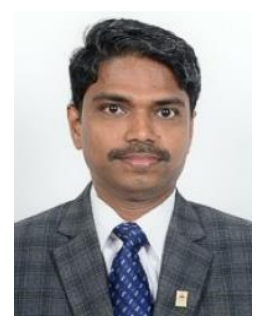

P. Dinesha is an Associate Professor in the Department of Mechanical and Manufacturing Engineering at Manipal Institute of Technology, Manipal Academy of Higher Education (MAHE), Manipal, India. MAHE is an outstanding private university having "Institute of Eminence" status declared by the Ministry of Human Resource Development, Government of India. Dr. Dinesha has obtained a doctoral degree from the National Institute of Technology Karnataka (NITK), Surathkal, India, in the area of alternative fuels. NITK is a preeminent institution of national importance established by the Indian Parliament and is consistently ranked within the top ten technical institutions in India. Dr. Dinesha has published more than 50 research papers in national and international journals and conferences. His research interests include pollution control, biofuel combustion, alternative fuels, biomass waste management, etc.

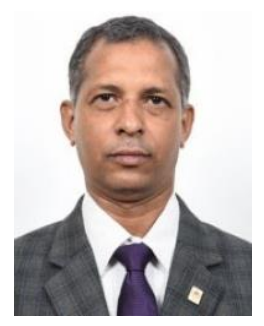

Shiva Kumar is an Associate Professor (Senior Scale) in the Department of Mechanical and Manufacturing Engineering at Manipal Institute of Technology, Manipal Academy of Higher Education (MAHE), Manipal, India. MAHE is an outstanding private university having "Institute of Eminence" status declared by the Ministry of Human Resource Development, Government of India. He obtained a doctoral degree from Visvesvaraya Technological University, Belagavi, India, in the area of internal combustion Engines. Dr. Kumar has published more than 50 research papers in national and international journals and conferences. His research interests include engine combustion, alternative fuels for IC engines, refrigeration and air conditioning, heat transfer, solar thermal conversion, CFD studies, and nanofluids.
[46] Venkatesan, E.P., Kandhasamy, A., Sivalingam, A., Kumar, A.S., Ramalingam, K., Joshua P.J.T., Balasubramanian, D., 2019. Performance and emission reduction characteristics of cerium oxide nanoparticle-water emulsion biofuel in diesel engine with modified coated piston. Environ. Sci. Pollut. Res. 26(26), 2736227371.

[47] Xin, Z., Tang, Y., Man, C., Zhao, Y., Ren, J., 2013. Research on the impact of $\mathrm{CeO}_{2}$-based solid solution metal oxide on combustion performance of diesel engine and emissions. J. Mar. Sci. Appl. 12(3), 374-379.

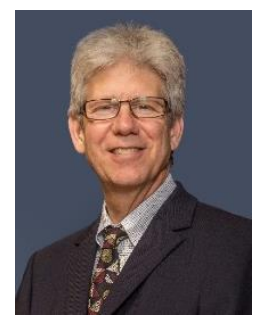

Marc A. Rosen is a Professor at the University of Ontario Institute of Technology in Oshawa, Canada, where he served as founding Dean of the Faculty of Engineering and Applied Science. Dr. Rosen was President of the Engineering Institute of Canada. A registered Professional Engineer in Ontario, he serves as Editor-in-Chief of several journals and was a Director of Oshawa Power and Utilities Corporation. With over 60 research grants and contracts and 900 publications, Dr. Rosen is active in sustainable energy, environmental impact, and energy technology (including renewable energy and efficiency). Much of his research has been carried out for industry, and he has written numerous books. Dr. Rosen has worked for such organizations as Imatra Power Company in Finland, Argonne National Laboratory near Chicago, and the Institute for Hydrogen Systems near Toronto. Dr. Rosen has received numerous awards and honors and is a fellow of several societies and organizations. 